\title{
The «System 3+3» in a Problem of Searching of a New Paradigm in Psychiatry
}

\author{
Rosman SV* \\ Physician of Functional Diagnostics of SBIH, Regional Psychoneurological Clinic, Russia
}

Submission: May 17,2018; Published: May 31, 2018

*Corresponding author: Rosman SV, Physician of functional diagnostics of SBIH, Regional Psychoneurological Clinic, Tver, Russian Federation, Russia, Tel: +7-903-800-11-05; Email: seros2005@mail.ru

Abstract

In article are presented possibilities of a unique method of diagnosis of mental diseases - the dispersion of amplitude-frequency characteristics of an alpha rhythm (DAFCAR) from positions of paradigm shift of the psychiatry based on the dimensions research techniques.

Keywords: Dispersion of amplitude-frequency characteristics of an alpha rhythm; Diagnosis of mental diseases; Paradigm shift of psychiatry

Abbreviations: DAFCAR: Dispersion of Amplitude-Frequency Characteristics of the Alpha Rhythm EEG; NGNB: Neuron-Glial Network of the Brain; HVT: Hyperventilation Test; CD cl: Coefficient of Dispersion of Alpha-Rhythm EEG-1 (the quotient of the modal values of power of alpha rhythm to his total power in the range of 7-13Hz); CD 22: Coefficient of Dispersion of the Alpha-Rhythm EEG-2 (the quotient of the power of the alpha rhythm in the range of "a modal value $\pm 0.5 \mathrm{~Hz}$ " to his total power in the range of $7-13 \mathrm{~Hz}$ ); Mof: Value of the Modal Frequencies; IIDA: Integral Index of Dispersion of the Alpha Rhythm EEG (Value of the Kurtosis of the Normal Distribution CDal in the Occipital Electrodes); ADA: Asymmetry Distribution of the Alpha Rhythm EEG (Value of the Asymmetry Distribution CDol in the Occipital Electrodes); IIH: Value of the Index Hypofrontality (Kurtosis of the Normal Distribution CD $\alpha$ l in the Frontal Electrodes); AH: Value of the Asymmetry of CDol in the Frontal Electrodes

\section{Introduction}

In the conditions of the informational revolution which is taking place now in the world, the problem of mental diseases gains prime value. And business even not that load of mentality of people with introduction of new informational technologies and attempts of impact on mentality for the purpose of strengthening of ability to perception of information amplified. The matter is that we need to reconsider in general the relation to a substance of information per se. Without pressing deeply in philosophical aspects of this problem, in relation to psychiatry it is possible to tell that it has to replace the paradigm. Need of it is shown in many scientific publications lighting a condition of the modern psychiatry.

Unfortunately, achievements of the modern science in this area very modest - still it was not succeeded to coordinate patho-psychological effects to organic violations in a brain. The simple fact is the main reason of it that still there are no objective methods of researches of neuronic and glial network of a brain (NGSB) which data would correlate with clinic of mental diseases [1].

Therefore still the psychiatry and psychology remain syndrome-based sciences, despite attempts to present methods of testing and creation of expert rating scales as methods of dimensions approach to diagnostics of mental diseases. The World Psychiatry [2] magazine outlined this problem as need of searching of the new paradigm which is the cornerstone of ideas of how the brain works. It is naive to assume that some research technique, without comparison to other methods and a clinical picture, can apply for a role of a marker of a mental disease. However, creation of such research is capable to lay the foundation in the theory of ideas of interrelation between psychopathology and violations in NGSB.

Within the last decade attempts of creation of such research on the basis of long ago known method - an electroencephalography (EEG) $[3,4]$, the brain which is traditionally considered as a nonspecific method of assessment of activity were made. The problem of an EEG was that only existence of epileptiform elements was recognized pathognomonic particular pathology of epilepsy. Other elements of a range of an EEG did not show such properties, differing in so big variability that it did not allow to create the system of normative indexes. Only the alpha-rhythm of the EEG spectrum showed certain regularity in changing its frequency in the ontogenetic development of the organism and in psychopathology [4]. 
Based on these properties an alpha of a rhythm the new research technique of dispersion of its amplitude-frequency characteristics (DAFCAR) was created. Idea that the deviation of distribution of an alpha rhythm on its frequency in a range from normal and an exit of its modal value for limits of norm is a marker of violation of the functional capacity of NGSGM became the main idea of this concept. Modal value of frequency of an alpha rhythm it is considered to be that frequency with which the power of a range is maximal (on graphics of a range it is the frequency corresponding to the maximal peak). At inspection of 2235 patients it was established that the relation of the maximal power of an alpha rhythm to cooperative power in the range of $7-13 \mathrm{~Hz}$ (Kda1) can be an indicator of a disintegration of an alpha rhythm and correlates about severity of organic damage of a brain (Figure 1) [5].

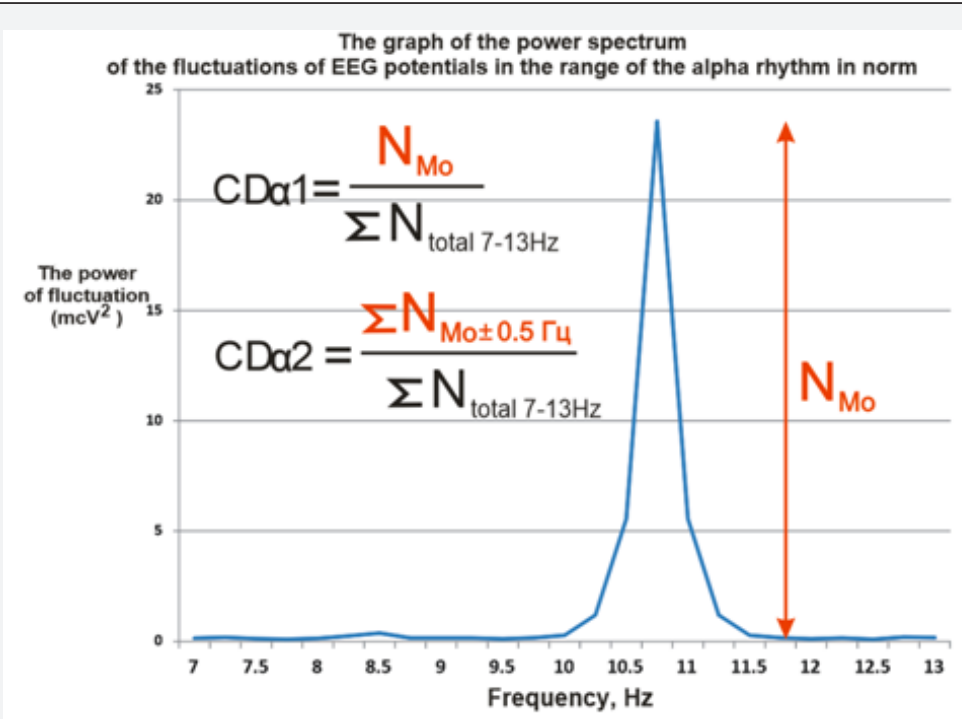

Figure 1: Calculation of $C D a 2$ and $C D a 1 i$ values for each assignment for each value of frequency of an alpha rhythm: CDa1 - the relation of the maximal power (with a modal frequency) an alpha rhythm (the central modal value) to its cooperative power in this assignment in the range of $7-13 \mathrm{~Hz}$; CDa2 - the alpha rhythm power relation in an interval "the frequency of modal power of $\pm 0,5 \mathrm{~Hz}$ " to cooperative power in this assignment.
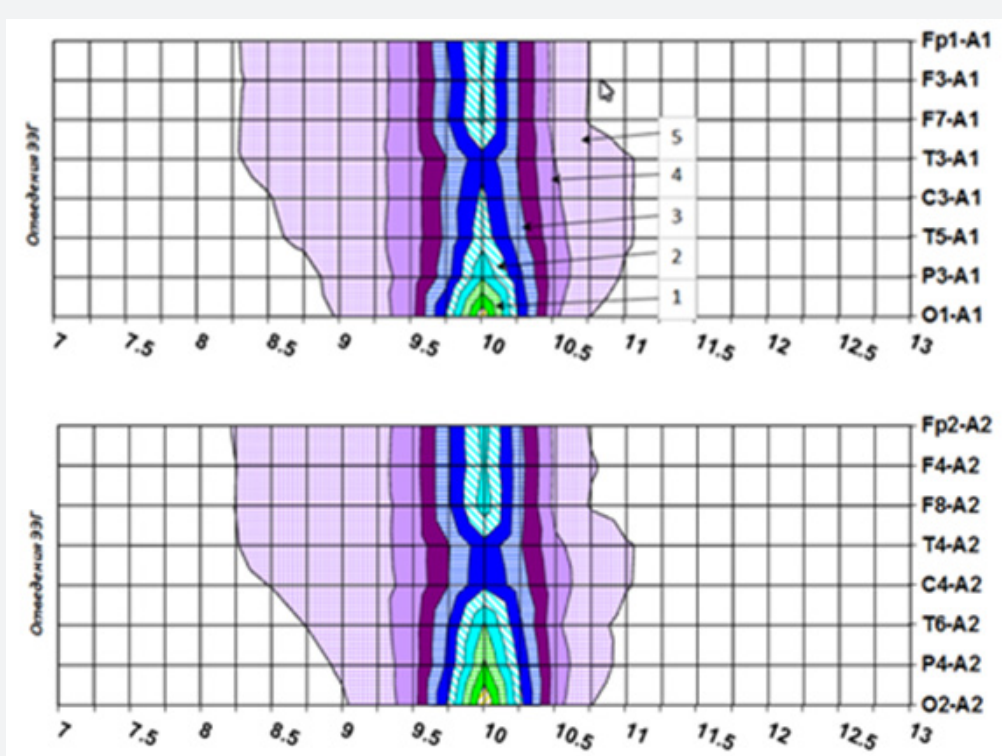

Частота альфа-ритма, Гц

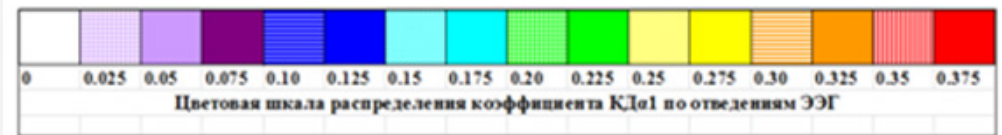

Figure 2: The average dispersion index in normal (top - left hemisphere, bottom - right hemisphere). 


\section{Global Journal of Addiction \& Rehabilitation Medicine}

Table 1: The contingent of patients with mental diseases studied by means of the DAFCAR method.

\begin{tabular}{|c|c|c|c|}
\hline \multirow{2}{*}{ Diagnostic groups (ICD-10) } & \multicolumn{2}{|c|}{ Gender } & \multirow{2}{*}{ Total } \\
\hline & $\mathbf{m}$ & $\mathbf{w}$ & \\
\hline F00 Alzheimer's disease & 4 & 13 & 17 \\
\hline F01 Vascular dementia... & 61 & 99 & 160 \\
\hline F02 Dementia of various genesis ... & 528 & 233 & 761 \\
\hline F00-F09 Organic mental disorders... & 641 & 225 & 866 \\
\hline F10-F19 Mental and behavioral disorders due to psychoactive substance use (alcohol) & 587 & 129 & 716 \\
\hline F10-F19 Mental and behavioral disorders due to psychoactive substance use (drugs) & 50 & 13 & 63 \\
\hline F20 Schizophrenia ... & 747 & 437 & 1184 \\
\hline F21-F25 Shizotypical and crazy disorder & 121 & 78 & 199 \\
\hline F30-F39 Mood (affective) disorders & 12 & 36 & 48 \\
\hline F40-F48 Neurotic, stress-related and somatoform disorders & 22 & 18 & 40 \\
\hline F60 Personal disorders & 954 & 37 & 991 \\
\hline F70 Mental retardation mild & 917 & 102 & 1019 \\
\hline F71 Mental retardation moderate & 129 & 41 & 170 \\
\hline F72 Mental retardation heavy & 16 & 7 & 23 \\
\hline F8x-F9x of Disorder of psychological development and behavior... & 83 & 40 & 123 \\
\hline Total & 4872 & 1508 & 6380 \\
\hline
\end{tabular}

Table 2: Distribution on an age of the contingent of the patients with mental diseases studied by means of the DAFCAR method.

\begin{tabular}{|c|c|c|c|}
\hline \multirow{2}{*}{ Age (according to the WHO classification) } & \multicolumn{2}{|c|}{ Gender } & \multirow{2}{*}{ Tota } \\
\hline & $\mathbf{m}$ & $\mathbf{w}$ & \\
\hline Children's & 439 & 125 & 564 \\
\hline Young & 2349 & 307 & 2656 \\
\hline Mature & 938 & 349 & 1287 \\
\hline Average & 781 & 437 & 1218 \\
\hline Elderly & 314 & 226 & 540 \\
\hline Senile & 51 & 64 & 115 \\
\hline TOTAL & 4872 & 1508 & 6380 \\
\hline
\end{tabular}

If in a graphic look to imagine value distribution $\operatorname{CD} \alpha 1$ on the surface of a brain and to develop them on representation of frequencies of a range of an alpha rhythm, then we will receive a dispersion cartogram of DAFCAR [6] (Figure 2). Mathematical expression of distribution $\mathrm{CD} \alpha 1$ in each assignment are the DAFCAR indexes which are coefficients of a normal distribution - an excess (IIDA and IIG) and asymmetry (ADA and AH) [7]. About the help of a technique of DAFCAR correlative researches of compliance of indexes of DAFCAR in various psychopathology are conducted (Tables $1 \& 2$ ). The following regularities are revealed:

a) Increase of degree of expressiveness of psychopathology is directly bound to decrease in frequency of an alpha rhythm common or regional.

b) Emergence of psychopathology at the common or local deviation of distribution Kda1 was observed from normal (an alpha rhythm desintegration) even if the modal value of an alpha rhythm was normal.

c) Variety of combinations of the violations reflected by dispersion cartograms and the DAFCAR indexes allow establishing statistical probability of category of a mental disease at surveyed.

Dependence of degree of expressiveness of psychopathology 


\section{Global Journal of Addiction \& Rehabilitation Medicine}

on decrease in the DAFCAR index it is presented in Figure 3. Summary ideas of correlation the patopsikhologicheskikh of phenomena and indexes of DAFCAR are presented in Table 3. Private results on separate are presented to categories of psychopathology in the published articles [8-12]. Why the representations which are the cornerstone of a new paradigm of psychiatry and psychology are called "system $3+3$ "? The main thing in it are 3 main actions which are the cornerstone of the informational exchange which is the cornerstone of mentality of the person. On the basis of a regularity of interaction of these principles 3 criteria of a mental condition of the person are created.

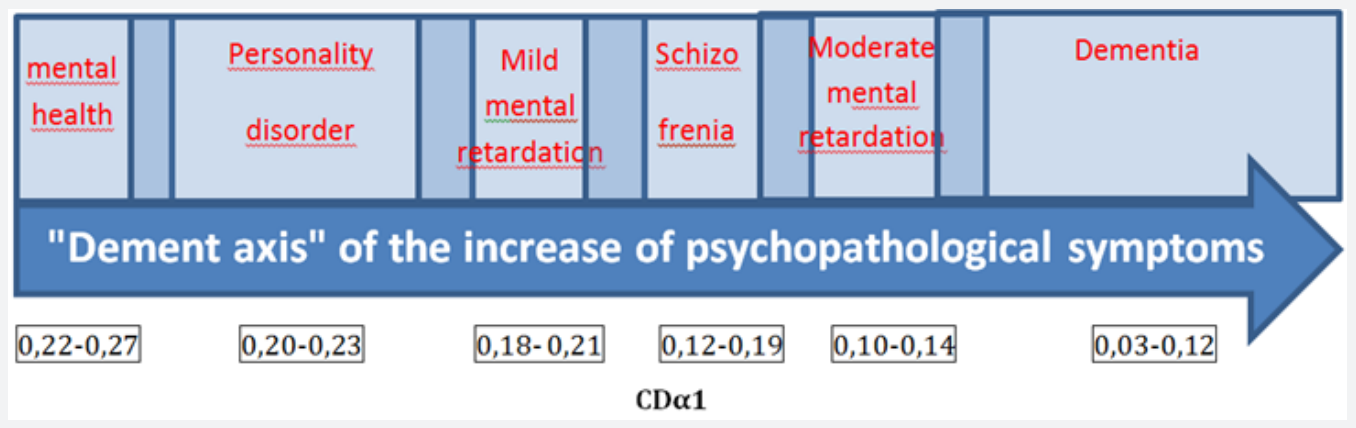

Figure 3: "Axis of dementia" of the matching indexes, DAFCAR and distribution of some of the major forms of mental illness.

Table 3: Compliance of the DAFCAR parameters of expressiveness pathopsychological phenomena.

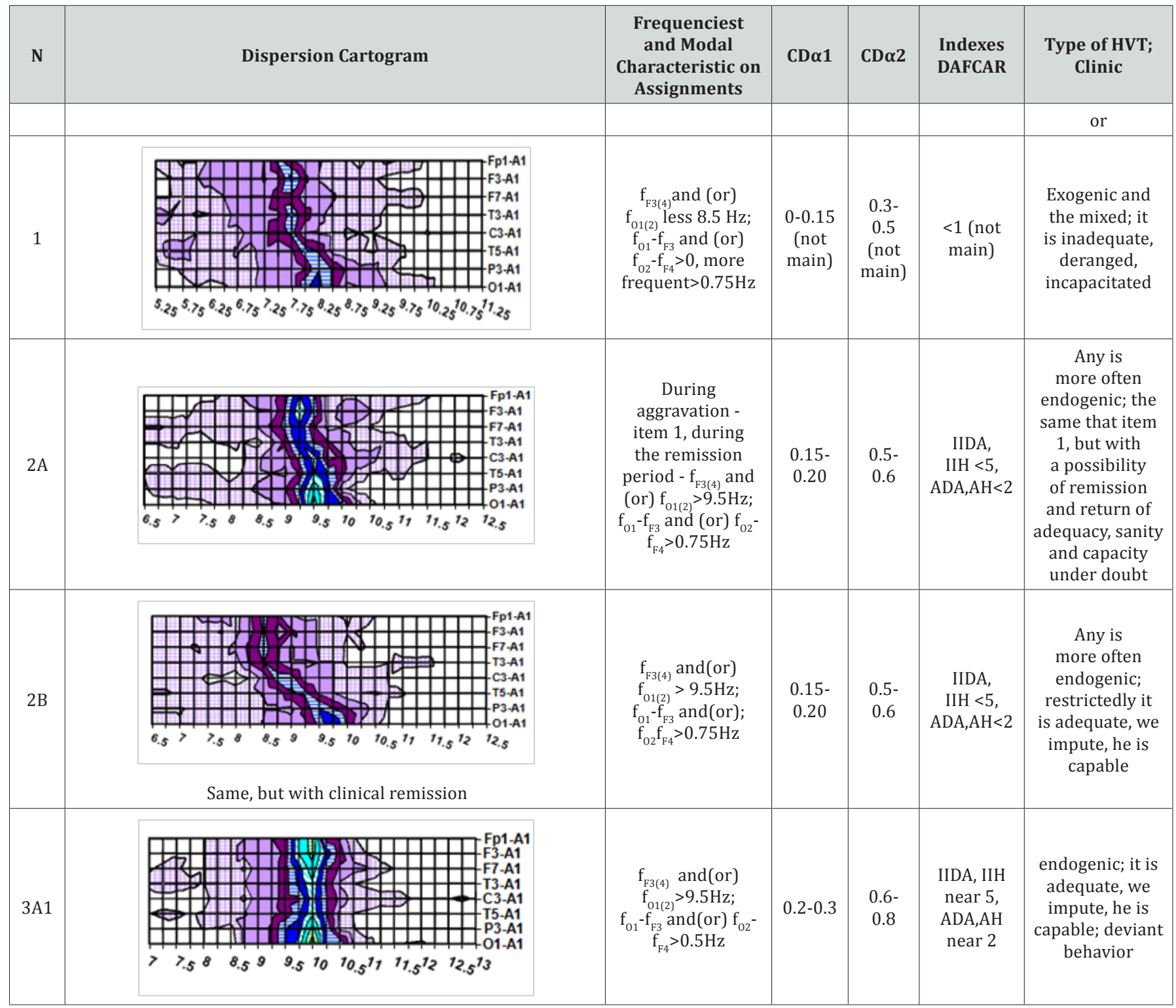




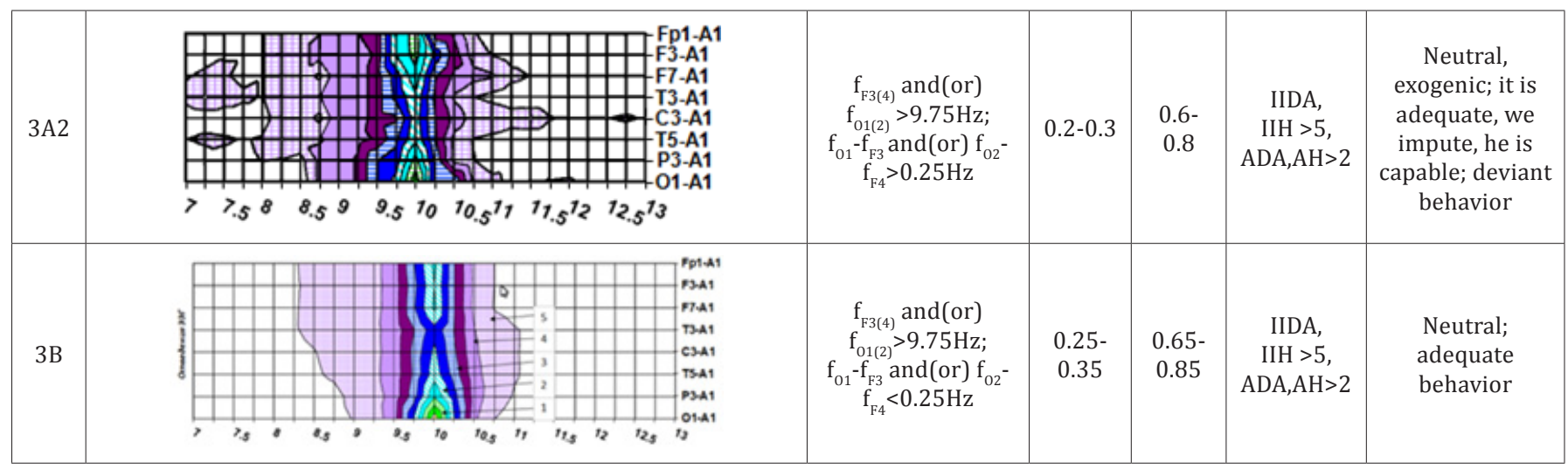

\section{Informational Bases of Formation of Mentality of the Person}

a) Process of afferent synthesis of the entering information - internalization of information

b) Creation on the basis of afferent synthesis of system of semantic images of an environmental real

c) Formation on the basis of the system of semantic images of socially acceptable behavior models in the form of the efferent answer

\section{Main Criteria of a Mental Condition of the Person}

a) The normal state of mentality - on the basis of reference afferent synthesis is created the system of semantic images of an environmental real, congruent for this look, on the basis of which socially acceptable behavior models of an individual are created

b) The psychopathology - violation of normal process of afferent synthesis, in result of what is created pathological polysemantic of images of an environmental real on the basis of which socially unacceptable behavior models of an individual are formed

c) A marker of process of violation of afferent synthesis is the degree of an entropy of NGSB, which is shown in DAFCAR.

What can give us broad application of the DAFCAR method, naturally, after versatile clinical check?

a) Change of fundamental ideas of an essence of informational process in a brain and development of a fractal neurophysiology

b) Obtaining the objective data explaining a genesis of behavioral features of the person

c) Early diagnostics of level of neurophysiological maturing of a brain at children for the purpose of early correction of deviations in this process and developments of optimum tactics of biotic strategy of patients

d) Monitoring in the course of development of new "physiologic" methods of correction of violations in NGSB e) Early diagnostics of probability of deviant behavior in population for the purpose of early prophylaxis of illegal violent acts

f) Screening among the contingent of applicants for work in the conditions of high public risk (pilots, dispatching service, drivers of public motor transport, military personnel, employees of law enforcement agencies)

g) Early diagnosis of mental diseases and behavioral violations; dynamic control of pathological process and the carried-out therapy; objective control of development of new methods of treatment of psychopathological violations.

It is thought that it is necessary to pass from condolences to the victims of people with inadequate behavior to the fissile objective identification of psychopathology into population populations for prophylaxis of similar incidents. The technique of DAFCAR is rather simple and does not demand the long-lived preparation for assessment of results therefore it can be easily applied in screening inspections.

\section{References}

1. Iznak AF (1989) Modulation of sensory-motor human activity on the background of alpha-rhythm EEG. Problems of development of scientific research in the field of mental health p. 3-24.

2. Rosman SV (2014) Integral indexes of dispersion of amplitudefrequency characteristics of an alpha rhythm of an EEG in diagnosis of mental diseases. Mental health 1: 132-135.

3. Ivanov LB (2016) Psyco-phisiological interpretation of the functional state of the brain using EEG. Bullet of clin neurophysiology 1: 5-26.

4. Kustubayeva AM (2012) Age dynamics of rhythms of electric activity of a brain: Uroven uneasiness and EEG indexes. Expert psychology 3: 5-20.

5. Rosman S, Kurakhina O (2017) Violent Crime in the Context of Entropy Neuron-Glial Networks of the Brain. Glob J Add \& Rehab Med 2(5): 555599.

6. Rosman S (2017) The Theoretical Foundations of Dispersion of Amplitude-Frequency Characteristics of the Alpha Rhythm of the EEG. Glob J Add \& Rehab Med 2(3): 555587.

7. Rosman SV (2013) Diagnostic capabilities of dispersion mapping the alpha rhythm of the electroencephalogram. Mental health 6: 64-69.

8. Rosman SV, Shpak LV (2013) New approaches to the assessment of polymorphism of the alpha rhythm EEG in psychiatric disorders. Ment Health 2: 39-44. 
9. Rosman SV (2017) Borderline Personality Disorder in the Context of Entropy Neuron-Glial Networks of the Brain. Glob J Add \& Rehab Med 2(4): 555595.

10. Rosman SV (2017) Burnout Syndrome in the Context of Entropy Neuron-Glial Networks of the Brain. Glob J Add \& Rehab Med 3(3): 555611.
11. Rosman SV (2017) Pedophilia in the Context of Entropy Neuron Glial Networks of the Brain. Glob J Add \& Rehab Med 4(2): 555632.

12. Sanislow CA (2016) Updating the research domain criteria. World Psychiatry 15(3): 222-223.

Your next submission with Juniper Publishers will reach you the below assets

- Quality Editorial service

- Swift Peer Review

- Reprints availability

- E-prints Service

- Manuscript Podcast for convenient understanding

- Global attainment for your research

- Manuscript accessibility in different formats

( Pdf, E-pub, Full Text, Audio)

- Unceasing customer service

Track the below URL for one-step submission https://juniperpublishers.com/online-submission.php 